\title{
No association of multiple type 2 diabetes loci with type 1 diabetes
}

\author{
S. M. Raj • J. M. M. Howson • N. M. Walker • \\ J. D. Cooper • D. J. Smyth • S. F. Field • H. E. Stevens • \\ J. A. Todd
}

Received: 9 December 2008 / Accepted: 16 April 2009/Published online: 20 May 2009

(C) The Author(s) 2009. This article is published with open access at Springerlink.com

\begin{abstract}
Aims/hypothesis We used recently confirmed type 2 diabetes gene regions to investigate the genetic relationship between type 1 and type 2 diabetes, in an average of 7,606 type 1 diabetic individuals and 8,218 controls, providing $>80 \%$ power to detect effects as small as an OR of 1.11 at a false-positive rate of 0.003 .

Methods The single nucleotide polymorphisms (SNPs) with the most convincing evidence of association in 12 type 2 diabetes-associated gene regions, $P P A R G, C D K A L 1$, HNF1B, WFS1, SLC30A8, CDKN2A-CDKN2B, IGF2BP2, KCNJ11, TCF7L2, FTO, HHEX-IDE and THADA, were analysed in type 1 diabetes cases and controls. $P P A R G$ and $H H E X-I D E$ were additionally tested for association in 3,851 type 1 diabetes families. Tests for interaction with HLA class II genotypes, autoantibody status, sex, and ageat-diagnosis of type 1 diabetes were performed with all 12 gene regions.

Results Only PPARG and HHEX-IDE showed any evidence of association with type 1 diabetes cases and controls $(p=$ 0.004 and $p=0.003$, respectively; $p>0.05$ for other SNPs). The potential association of PPARG was supported by family analyses $\left(p=0.003 ; p_{\text {combined }}=1.0 \times 10^{-4}\right)$. No SNPs showed evidence of interaction with any covariate $(p>0.05)$.
\end{abstract}

Electronic supplementary material The online version of this article (doi:10.1007/s00125-009-1391-y) contains supplementary material, which is available to authorised users.

S. M. Raj · J. M. M. Howson · N. M. Walker · J. D. Cooper •

D. J. Smyth $\cdot$ S. F. Field $\cdot$ H. E. Stevens $\cdot$ J. A. Todd $(\triangle)$

Juvenile Diabetes Research Foundation/Wellcome Trust Diabetes and Inflammation Laboratory,

Cambridge Institute for Medical Research,

University of Cambridge,

Wellcome Trust/MRC building, Hills Road,

Cambridge CB2 0XY, UK

e-mail: john.todd@cimr.cam.ac.uk
Conclusions/interpretation We found no convincing genetic link between type 1 and type 2 diabetes. An association of PPARG (rs1801282/Pro12Ala) could be consistent with its known function in inflammation. Hence, our results reinforce evidence suggesting that type 1 diabetes is a disease of the immune system, rather than being due to inherited defects in beta cell function or regeneration or insulin resistance.

Keywords Age-at-diagnosis - Association study · Autoantibodies · Genetics - PPARG - SLC30A8.

Type 1 diabetes . Type 2 diabetes

$\begin{array}{ll}\text { Abbreviations } \\ \text { GWA } & \text { Genome-wide association } \\ \text { IA-2 } & \text { Insulinoma-associated antigen 2 } \\ \text { MAF } & \text { Minor allele frequency } \\ \text { SNP } & \text { Single nucleotide polymorphism } \\ \text { T1DGC } & \text { Type 1 Diabetes Genetics Consortium } \\ \text { TPO } & \text { Thyroid peroxidase } \\ \text { WTCCC } & \text { Wellcome Trust Case Control Consortium }\end{array}$

\section{Introduction}

The possible relationship between type 1 and type 2 diabetes is a controversial subject. Formally, the two are considered to be aetiologically distinct. Type 1 diabetes is characterised by autoimmune destruction of pancreatic beta cells, resulting in a failure to produce insulin. Type 2 diabetes is caused by impaired beta cell function and capacity to secrete insulin, coupled to a decline in tissue sensitivity to insulin. Owing to similarities in their clinical manifestation, especially in a form of type 1 diabetes 
diagnosed in adulthood (latent autoimmune diabetes in adults), it has been suggested that type 1 and type 2 diabetes may share a common pathophysiological aetiology [1-3]. Therefore, we sought to investigate this hypothesis by investigating if genetic variants that predispose individuals to type 2 diabetes risk are associated with type 1 diabetes.

Currently, due mainly to the success of genome-wide association (GWA) studies, there are 18 confirmed type 2 diabetes loci: PPARG, CDKAL1, HNF1B, WFS1, SLC30A8, CDKN2A-CDKN2B, IGF2BP2, KCNJ11, TCF7L2, FTO, HHEX-IDE, JAZF1, CDC123-CAMK1D, TSPAN8-LGR5, THADA, ADAMTS9, NOTCH2 and, most recently, KCNQ1 [4-16] (Electronic supplementary material [ESM] Tables 1 and 2). Six of these regions were identified in a metaanalysis that combined three GWA studies, and were confirmed in an independent set of up to 14,157 cases and 43,209 controls, by Zeggini et al. [5] (ESM Table 2). The effects of the 18 chromosome regions on type 2 diabetes risk have ORs ranging from 1.09 to 1.37 using single nucleotide polymorphisms (SNPs) [4-16] (Table 1; ESM Tables 1 and 2).

We have previously evaluated the association of five type 2 diabetes gene regions with type 1 diabetes. The gene regions KCNJ11, IRS1 and PPARG were analysed in 2,434 type 1 diabetes families, and the PPARG rs 1801282 (Pro12Ala) variant was found to have a RR of $0.87, p=$ 0.008 [17]. In two recent studies, TCF7L2 and FTO showed no evidence of association with type 1 diabetes in approximately 6,000 cases and 7,000 controls [18, 19]. We have now expanded the size of our sample sets to maximise the statistical power of our study: we have, in theory, $89 \%$ power to find effects as small as an OR of 1.11 at an $\alpha$ level of 0.003 for the mean minor allele frequency (MAF) of 0.28 in 7,606 cases and 8,218 controls, assuming a multiplicative model. The present study, therefore, is a comprehensive analysis of 12 known type 2 diabetes loci, including tests of interactions with HLA class II genotypes, using the $H L A-D R B 1^{*} 03$ - and $H L A-D R B 1^{*} 04$-tagging SNPs rs7454108 and rs2187668, age-at-diagnosis of type 1 diabetes, sex and autoantibody status, to evaluate whether type 1 and type 2 diabetes share a common genetic background.

\section{Methods}

Case-control samples An average of 7,606 British type 1 diabetes cases and 8,218 British controls, all of whom were of white ethnicity, were genotyped. Type 1 diabetes cases were recruited for the Juvenile Diabetes Research Foundation/Wellcome Trust Diabetes and Inflammation Laboratory's Genetic Resource Investigating Diabetes British, type
1 diabetes collection (http://www.childhood-diabetes.org. uk/grid.shtml, accessed 22 April 2009). Cases had been diagnosed with type 1 diabetes before 17 years of age (mean age at diagnosis 7.8 years). Control DNA samples came from the British 1958 Birth Cohort $(n=7,733)$ and the Wellcome Trust Case Control Consortium's (WTCCC) UK Blood Service sample collection $(n=3,181)$ [20]. Cases and controls were matched in terms of place of recruitment and place of birth, respectively, for each of 12 geographical regions across Great Britain (southern England, southwestern England, south-eastern England, eastern England, London, Midlands, Wales, north-eastern England, north Midlands, East and West Ridings, northern England and Scotland) to minimise bias in our association results owing to varying disease prevalence and allele frequencies across Great Britain [20, 21]. The appropriate ethics committees approved the collection of all DNA samples, and written consent was obtained from all individuals, or from the parents of individuals who were too young to provide consent.

Family samples One SNP in PPARG (rs1801282) and one in the $H H E X-I D E$ region (rs1111875) were genotyped in 3,851 type 1 diabetes families of white European descent. The total comprised 593 multiplex (affected sib-pair) families from the Diabetes UK Warren I collection; 80 simplex families from Yorkshire, UK; 263 multiplex/ simplex families from Northern Ireland; 331 multiplex families from the Human Biological Data Interchange, USA; 951 multiplex/simplex families from Finland; 410 simplex families from Romania; 357 simplex families from Norway and 866 affected sib-pair families made available through the Type 1 Diabetes Genetics Consortium (T1DGC; http://www.t1dgc.org, accessed 22 April 2009; http://www-gene.cimr.cam.ac.uk/todd/dna-refs.shtml, accessed 22 April 2009). Of the T1DGC families, 166 families were from the Asia-Pacific region, 422 families were from across Europe and 278 were from North America.

Genotyping Samples were genotyped by personnel blind to case-control status using the Taqman 5' nuclease assay (Applied Biosystems, Warrington, UK) according to the manufacturer's protocol. To minimise error, two operators independently scored the genotypes. Previously published genotypes at FTO, TCF7L2 and PPARG were also included [17-19] as a subset of our present dataset. The present study includes up to 3,363 additional type 1 diabetes cases and controls. A full description of genotypes common to the current and previously published data is provided in ESM Table 3. We genotyped a minimum of 5,896 cases and 7,101 controls and a maximum of 8,229 cases and 10,406 controls, depending 
Table 1 Association analysis of type 2 diabetes loci in type 1 diabetes cases and controls

\begin{tabular}{|c|c|c|c|c|c|c|c|c|c|c|c|}
\hline \multirow[t]{2}{*}{$\begin{array}{l}\text { Gene } \\
\text { region }\end{array}$} & \multirow[t]{2}{*}{ SNP } & \multirow[t]{2}{*}{$\begin{array}{l}\text { Cases, } \\
n\end{array}$} & \multirow[t]{2}{*}{$\begin{array}{l}\text { Controls, } \\
n\end{array}$} & \multicolumn{2}{|c|}{$\begin{array}{l}\text { Minor allele, Number } \\
\text { of chromosomes } \\
\text { (allele frequency) }\end{array}$} & \multirow[t]{2}{*}{$\begin{array}{l}\text { OR } \\
(95 \% \mathrm{CI})^{\mathrm{a}}\end{array}$} & \multirow[t]{2}{*}{$\begin{array}{l}p \\
\text { value }\end{array}$} & \multirow[t]{2}{*}{$\begin{array}{l}\text { Power, } \\
\%^{\mathrm{b}}\end{array}$} & \multirow[t]{2}{*}{$\begin{array}{l}\text { Power, } \\
\%^{\mathrm{c}}\end{array}$} & \multicolumn{2}{|c|}{$\begin{array}{l}\text { Type } 2 \\
\text { diabetes }^{\mathrm{d}}\end{array}$} \\
\hline & & & & Cases & Controls & & & & & OR & Ref. \\
\hline \multirow[t]{2}{*}{ TCF $7 L 2$} & $\begin{array}{l}\text { rs7903146 } \\
(\mathrm{C}>\mathrm{T})^{\mathrm{e}}\end{array}$ & 5,896 & 7,322 & $\begin{array}{l}3,395 \\
(0.29)\end{array}$ & $\begin{array}{l}4,260 \\
(0.29)\end{array}$ & $\begin{array}{l}0.99 \\
(0.94-1.05)\end{array}$ & 0.744 & 81 & 100 & 1.37 & {$[8,15]$} \\
\hline & $\begin{array}{l}\text { rs } 12255372 \\
(G>T)\end{array}$ & 7,776 & 8,847 & $\begin{array}{l}4,421 \\
(0.28)\end{array}$ & $\begin{array}{l}5,125 \\
(0.29)\end{array}$ & $\begin{array}{l}0.97 \\
(0.92-1.02)\end{array}$ & 0.235 & 92 & 100 & 1.52 & [9] \\
\hline $\begin{array}{l}C D K N 2 A- \\
B\end{array}$ & $\begin{array}{l}\text { rs } 10811661 \\
(T>C)\end{array}$ & 7,634 & 7,148 & $\begin{array}{l}2,754 \\
(0.18)\end{array}$ & $\begin{array}{l}2,498 \\
(0.17)\end{array}$ & $\begin{array}{l}1.03 \\
(0.97-1.09)\end{array}$ & 0.354 & 68 & 100 & 0.83 & $\begin{array}{l}{[4,8,} \\
15]\end{array}$ \\
\hline FTO & $\begin{array}{l}\text { rs9939609 } \\
(T>A)^{e}\end{array}$ & 7,655 & 7,182 & $\begin{array}{l}6,098 \\
(0.40)\end{array}$ & $\begin{array}{l}5,644 \\
(0.39)\end{array}$ & $\begin{array}{l}1.03 \\
(0.98-1.08)\end{array}$ & 0.252 & 92 & 100 & 1.17 & {$[4,8]$} \\
\hline KCNJ11 & $\begin{array}{r}\mathrm{rs} 5219 \\
(\mathrm{C}>\mathrm{T})\end{array}$ & 8,058 & 10,406 & $\begin{array}{l}5,772 \\
(0.36)\end{array}$ & $\begin{array}{l}7,411 \\
(0.36)\end{array}$ & $\begin{array}{l}1.02 \\
(0.97-1.06)\end{array}$ & 0.501 & 97 & 100 & 1.14 & {$[8,15]$} \\
\hline $\begin{array}{c}H H E X_{-} \\
I D E\end{array}$ & $\begin{array}{l}\text { rs } 1111875 \\
(G>A)\end{array}$ & 7,968 & 9,675 & $\begin{array}{l}6,369 \\
(0.40)\end{array}$ & $\begin{array}{l}8,042 \\
(0.42)\end{array}$ & $\begin{array}{l}0.94 \\
(0.90-0.98)\end{array}$ & 0.003 & 97 & 100 & 0.88 & $\begin{array}{l}{[4,8,} \\
15]\end{array}$ \\
\hline$I G F 2 B P 2$ & $\begin{array}{l}\mathrm{rs} 4402960 \\
(\mathrm{G}>\mathrm{T})\end{array}$ & 7,554 & 7,101 & $\begin{array}{l}4,755 \\
(0.31)\end{array}$ & $\begin{array}{l}4,546 \\
(0.32)\end{array}$ & $\begin{array}{l}0.98 \\
(0.93-1.03)\end{array}$ & 0.457 & 89 & 99 & 1.14 & $\begin{array}{l}{[4,8,} \\
15]\end{array}$ \\
\hline$C D K A L 1$ & $\begin{array}{l}\text { rs77569992 } \\
(A>G)\end{array}$ & 7,714 & 7,200 & $\begin{array}{l}4,185 \\
(0.27)\end{array}$ & $\begin{array}{l}3,893 \\
(0.27)\end{array}$ & $\begin{array}{l}1.00 \\
(0.95-1.05)\end{array}$ & 0.957 & 86 & 100 & 1.20 & [11] \\
\hline$S L C 30 A 8$ & $\begin{array}{l}\text { rs } 13266634 \\
(C>T)\end{array}$ & 7,680 & 7,200 & $\begin{array}{l}4,879 \\
(0.32)\end{array}$ & $\begin{array}{l}4,463 \\
(0.31)\end{array}$ & $\begin{array}{l}1.04 \\
(0.99-1.09)\end{array}$ & 0.146 & 89 & 93 & 0.89 & $\begin{array}{l}{[4,8,} \\
15]\end{array}$ \\
\hline WFS1 & $\begin{array}{l}\text { rs } 10010131 \\
(\mathrm{G}>\mathrm{A})\end{array}$ & 7,745 & 9,259 & $\begin{array}{l}6,173 \\
(0.40)\end{array}$ & $\begin{array}{l}7,564 \\
(0.41)\end{array}$ & $\begin{array}{l}0.96 \\
(0.92-1.00)\end{array}$ & 0.065 & 96 & 96 & 0.90 & [12] \\
\hline$H N F 1 B$ & $\begin{array}{l}\text { rs7501939 } \\
(\mathrm{C}>\mathrm{T})\end{array}$ & 7,712 & 7,217 & $\begin{array}{l}6,249 \\
(0.41)\end{array}$ & $\begin{array}{l}5,800 \\
(0.40)\end{array}$ & $\begin{array}{l}1.01 \\
(0.97-1.06)\end{array}$ & 0.554 & 93 & 85 & 1.10 & [13] \\
\hline PPARG & $\begin{array}{l}\text { rs } 1801282 \\
(\mathrm{C}>\mathrm{G})\end{array}$ & 8,229 & 9,342 & $\begin{array}{l}1,880 \\
(0.11)\end{array}$ & $\begin{array}{l}2,304 \\
(0.12)\end{array}$ & $\begin{array}{l}0.91 \\
(0.85-0.97)\end{array}$ & 0.004 & 60 & 82 & 0.88 & $\begin{array}{l}{[4,8,} \\
15]\end{array}$ \\
\hline \multirow[t]{2}{*}{ THADA } & $\begin{array}{l}\text { rs7578597 } \\
(\mathrm{T}>\mathrm{C})\end{array}$ & 7,601 & 8,395 & $\begin{array}{l}1,598 \\
(0.11)\end{array}$ & $\begin{array}{l}1,840 \\
(0.11)\end{array}$ & $\begin{array}{l}0.94 \\
(0.88-1.01)\end{array}$ & 0.113 & 50 & 80 & 0.87 & {$[5]$} \\
\hline & $\begin{array}{l}\text { rs } 17031005 \\
(A>G)\end{array}$ & 7,256 & 8,760 & $\begin{array}{l}1,481 \\
(0.10)\end{array}$ & $\begin{array}{l}1,878 \\
(0.11)\end{array}$ & $\begin{array}{l}0.94 \\
(0.87-1.01)\end{array}$ & 0.078 & 50 & 80 & NA & - \\
\hline
\end{tabular}

${ }^{\mathrm{a}}$ The ORs and $95 \%$ CIs are for the minor allele using the common allele as the reference allele

${ }^{\mathrm{b}}$ Power calculated for an OR of 1.11 at an $\alpha$ level of 0.003 , assuming a multiplicative allelic effects model, given the allele frequency and number of type 1 diabetes cases and controls genotyped

${ }^{\mathrm{c}}$ Power calculated for the size of effect detected in type 2 diabetes at an $\alpha$ level of 0.003 , assuming a multiplicative allelic effects model, using the number of type 1 diabetes cases and controls genotyped

${ }^{\mathrm{d}}$ The ORs are those reported in the literature for an association with type 2 diabetes

${ }^{\mathrm{e}}$ New analyses of previously published data $[18,19]$ are included for information (ESM Table 3)

$C D K N 2 A-B$ denotes $C D K N 2 A-C D K N 2 B$

on the number of samples available at the time the SNPs were genotyped. The average success rate for sample scoring was $96.77 \%$, with a range of $95.20-97.75 \%$ across the 14 SNPs (ESM Table 4). The HLA classical loci, $H L A$ $D R B 1$ and $H L A-D Q B 1$ were genotyped in a subset of type 1 diabetes case samples $(n=3,312)$ as described previously [22]. Two HLA class II SNPs, rs7454108 and rs2187668, which tag the type 1 diabetes-predisposing DR3 and DR4 haplotypes, were also genotyped in the full case-control collection [23].

Autoantibody measurements Levels of to GAD, insulinomaassociated antigen 2 (IA-2) and thyroid peroxidase (TPO) were measured in plasma samples. TPO autoantibody was measured with a PLATO processor ELISA immunoassay (Phadia, Milton Keynes, UK), using recombinant TPO antigen standardised against the National Institute of Biological Standards and Controls standard serum 66/387. GAD and IA-2 autoantibodies were measured by the Department of Clinical Science at the University of Bristol (Bristol, UK), using a radioimmunoassay $[24,25]$. The threshold value for the presence of autoantibodies was taken as $85 \mathrm{IU} / \mathrm{ml}$ for TPO ( $n=969$ autoantibody-positive individuals), 6 WHO units/ml for IA-2 ( $n=1,521$ autoantibody-positive individuals), and 14 WHO units/ml for GAD ( $n=1,305$ autoantibodypositive individuals) $[26,27]$. 
Table 2 Association of PPARG and HHEX-IDE in type 1 diabetes families

\begin{tabular}{|c|c|c|c|c|c|c|c|c|}
\hline $\begin{array}{l}\text { Gene } \\
\text { region }\end{array}$ & SNP & $\begin{array}{l}\text { Families, } \\
n\end{array}$ & $\begin{array}{l}\text { Allele or } \\
\text { genotype }\end{array}$ & $\begin{array}{l}\text { Transmitted }{ }^{\mathrm{a}}, n \\
(\%)\end{array}$ & $\begin{array}{l}\text { Not transmitted }{ }^{\mathrm{a}} \text {, } \\
n(\%)\end{array}$ & RR $(95 \% \mathrm{CI})$ & $\begin{array}{l}p \\
\text { value }\end{array}$ & $\begin{array}{l}p_{\text {combined }} \\
\text { value }^{\mathrm{d}}\end{array}$ \\
\hline \multirow[t]{4}{*}{$P P A R G$} & \multirow[t]{4}{*}{ rs 1801282} & \multirow[t]{4}{*}{3,312} & G & $862(45.0)$ & $988(55.0)$ & $0.87(0.80-0.95)$ & \multirow[t]{3}{*}{$0.003^{\mathrm{b}}$} & \multirow[t]{4}{*}{$1.0 \times 10^{-4}$} \\
\hline & & & $\mathrm{C} / \mathrm{C}$ & $3,139(77.4)$ & $9,176(75.4)$ & 1.00 (reference) & & \\
\hline & & & $\mathrm{C} / \mathrm{G}$ & $853(21.0)$ & 2,789 (22.9) & $0.86(0.78-0.95)$ & & \\
\hline & & & $\mathrm{G} / \mathrm{G}$ & $65(1.6)$ & $206(1.7)$ & $0.84(0.62-1.15)$ & $0.010^{\mathrm{c}}$ & \\
\hline \multirow[t]{4}{*}{$H H E X-I D E$} & \multirow[t]{4}{*}{ rs1111875 } & \multirow[t]{4}{*}{3,229} & A & $1,728(49.8)$ & $1,742(50.2)$ & $0.99(0.93-1.06)$ & \multirow[t]{3}{*}{$0.812^{\mathrm{b}}$} & \multirow[t]{4}{*}{0.017} \\
\hline & & & $\mathrm{G} / \mathrm{G}$ & $1,283(34.8)$ & 3,855 (34.9) & 1.00 (reference) & & \\
\hline & & & $\mathrm{G} / \mathrm{A}$ & $1,788(48.6)$ & $5,324(48.2)$ & $1.01(0.92-1.10)$ & & \\
\hline & & & $\mathrm{A} / \mathrm{A}$ & $611(16.6)$ & 1,867 (16.9) & $0.98(0.85-1.12)$ & $0.880^{\mathrm{c}}$ & \\
\hline
\end{tabular}

\footnotetext{
${ }^{a}$ Note that the frequencies of genotypes in the cases and pseudo-controls are given, as well as the transmission counts from the transmission disequilibrium test analysis

${ }^{\mathrm{b}}$ The $p$ value for association from the transmission disequilibrium test, which assumes a multiplicative model

${ }^{\mathrm{c}}$ The $p$ value for association from the $2 d f$ conditional logistic regression model, which does not assume a specific mode of inheritance

${ }^{\mathrm{d}}$ The $p$ value obtained by combining the results of the case-control and family data set (please refer to the Methods for further details)
}

Statistical methods-association tests Statistical analyses were performed using Stata version 10 (http://www.stata. com, accessed 22 April 2009), using routines available from http://www-gene.cimr.cam.ac.uk/clayton/software/ stata/ (accessed 22 April 2009). We calculated power assuming a multiplicative effects model and an $\alpha$ level of 0.003 , as this is equivalent to an $\alpha$ level of 0.05 divided by 17 , the number of gene regions considered in the present report. All SNP genotypes were in Hardy-Weinberg equilibrium in the controls $(p \geq 0.07)$ and the parents $(p \geq$ $0.06)$. SNPs were tested for association using logistic regression with disease status as the dependent variable and the SNP to be tested coded 0,1 or 2 , corresponding to counts of the minor allele, as the predictor variable. Geographical region was included in the logistic model as strata within which SNP associations could be tested. To test which inheritance model was appropriate, we compared a multiplicative allelic effects model with a model that did not assume a specific mode of inheritance using a likelihood ratio test. The multiplicative model was appropriate for all SNPs $(p \geq 0.08)$. No correction was made for multiple comparisons.

The SNPs were tested for association in the families using the transmission disequilibrium test (TDT), which assumes a multiplicative allelic effects model. To test whether the multiplicative allelic effects model was appropriate, we used a conditional logistic regression model to compare sets of offspring with matched pseudo-controls (which consisted of the genotypes that could have been transmitted to the offspring but were not). The SNPs were modelled assuming no specific mode of inheritance, and were compared with the allelic effects model with a likelihood ratio test [28]. The multiplicative model was appropriate for both SNPs $(p>0.4)$. The $p$ values from the association tests in the case-control set and families were combined using Fisher's method. At the THADA SNP, rs17031005, we pooled information across multiple studies using Woolf's estimate of the common OR [29] and a Wald test on $1 d f$.

Statistical methods-interaction tests We tested for nonmultiplicative interaction effects between the SNPs and HLA class II genotypes in a case-only analysis. This test assumes that the HLA genotypes and the SNP of interest are conditionally independent in controls. The SNP genotype was entered into a regression model as the dependent variable, the HLA genotypes as the predictor variables, and geographical region as strata. Three different groupings of the HLA class II genotypes were considered, and these have been described in detail elsewhere [30]. The first approach grouped individuals into those positive or negative for the $H L A-D R B 1 * 03 / H L A-D R B 1 * 04$ genotype (where $H L A-D R B 1^{*} 03 / H L A-D R B^{*} 0403$ are classed as $H L A-D R B 1 * 03 / H L A-D R B 1 * 04$-negative, as were cases carrying the $H L A-D Q B 1^{*} 0301$ allele). The second approach used genotype risk estimates produced by Koeleman et al. [31] to categorise individuals as being at a high-, medium- or low-risk of type 1 diabetes based on HLA status. Third, we used recursive partitioning to divide the individuals into type 1 diabetes cases or controls based on their HLA class II genotype [22]. As classical HLA genotyping data were not available for the majority of the type 1 diabetes sample set, the SNPs rs74544108 and rs2187668 [23], which are in strong linkage disequilibrium with the $H L A-D R B 1^{*} 04$ and $H L A-D R B 1^{*} 03$ alleles (with $r^{2}=0.78$ and $r^{2}=0.97$, respectively), were used as tags. The genotypes ( $n=8,416$ cases) were coded as $3 / 3,3 / 4,3 / \mathrm{X}$, $4 / 4,4 / \mathrm{X}$ and $\mathrm{X} / \mathrm{X}$, with 3 and 4 corresponding to 
$H L A-D R B 1^{*} 03$ and $H L A-D R B 1^{*} 04$, respectively. X represented all other HLA class II alleles excluding the alleles $H L A-D R B 1^{*} 03$ and HLA-DRB $1^{*} 04$.

A case-only analysis was performed for age-at-diagnosis and sex, using genotype at the SNP of interest as the predictor variable, and sex (coded as a binary variable) or age-at-diagnosis (coded as a continuous variable) as the outcome variable in a regression model (logistic regression for sex and linear regression for age-at-diagnosis). We also tested all SNPs for interaction with age-at-diagnosis divided into quartiles $(0-4,5-7,8-10$ and $11-16$ years), using multinomial logistic regression. Interactions between the autoantibodies and SNP genotype were also tested in the cases. Each autoantibody was coded as a binary trait, corresponding to the presence or absence of the autoantibody, and was used as the dependent variable in a logistic model, with genotype at the test locus as the independent variable [27].

\section{Results}

The results of the association tests are summarised in Table 1. We found no convincing evidence of association between the type 1 and type 2 diabetes candidate genes in the case-control dataset, with the possible exceptions of PPARG (rs1801282 $p=0.004$, OR [95\% CI] 0.91 [0.850.97]) and $H H E X-I D E(\mathrm{rs} 1111875, p=0.003$, OR [95\% CI] 0.94 [0.90-0.98]) (Table 1; ESM Table 4). Hence, these two SNPs were further genotyped in a minimum of 3,229 families. The PPARG SNP rs1801282 had already been genotyped in a subset $(n=2,355)$ of these families [17] (ESM Table 3). By genotyping an additional 1,135 families the power for the detection of associations was increased.

The result we obtained for the SNP rs1801282 in the families was consistent with that obtained in the casecontrol collection $(p=0.003$, RR [95\% CI] 0.87 [0.80$0.95]$; Table $\left.2 ; p_{\text {combined }}=1 \times 10^{-4}\right)$. We obtained no additional support for an association of HHEX-IDE ( $p=$ 0.812 , RR [95\%CI] 0.99 [0.93-1.06]; Table 2) with type 1 diabetes in the families. Although none of these SNPs showed a convincing association with type 1 diabetes overall, we were interested in whether they may affect a subgroup of type 1 diabetes cases. Therefore, we tested for interaction between all the SNPs and HLA class II genotypes, autoantibody status, age-at-diagnosis and sex. We found no evidence of interaction effects between the HLA genotypes and the type 2 diabetes loci $(p>0.02)$ (ESM Table 5). We also found no evidence for an interaction between any of the autoantibodies and the type 2 diabetes SNPs $(p \geq 0.05)$. This included the SLC30A8 SNP rs13266634, which has been reported by Hutton and colleagues [32] to determine the specificity of ZnT8, a newly discovered type 1 diabetes autoantigen [33].

No evidence of interactions with age-at-diagnosis or sex with the SNP association with type 1 diabetes was found $(p \geq 0.05)$. Gohlke et al. [34] reported an association between early age-at-diagnosis $(<5$ years of age) and the SLC30A8 SNP rs13266634, and Wenzlau et al. [33] showed that ZnT8 autoantibodies appear before 3 years of age. Therefore, we also tested for interactions between the type 2 diabetes loci and age-at-diagnosis divided into quartiles, which included a group of individuals under 4 years of age, and found no evidence of interactions between age at diagnosis and the type 2 diabetes loci over any of the four age groups $(p>0.04$; ESM Table 6), except for some evidence at $C D K N 2 A-C D K N 2 B$ (rs10811661 $p=0.008$; ESM Table 6), which is unlikely to be a true result, taking into account the number of hypotheses tested.

Six recently reported type 2 diabetes gene regions, JAZF1, CDC123-CAMK1D, TSPAN8-LGR5, THADA, ADAMTS9 and NOTCH2, identified by a meta-analysis published by Zeggini et al. [5], were also analysed for association with type 1 diabetes in a meta-analysis by Cooper et al. [35] (results for nine type 2 diabetesassociated SNPs, from the Cooper et al. type 1 diabetes meta-analysis are given in ESM Table 2). The Cooper et al. [35] meta-analysis combined GWA data (305,090 SNPs) for 1,964 British type 1 diabetes cases and 2,953 controls from the WTCCC study [20] with data for 1,601 US type 1 diabetes cases from the Genetics of Kidneys in Diabetes study and 1,704 US controls from the National Institute of Mental Health [35], and hence included up to 3,565 cases and 4,657 controls. Three SNPs with the most convincing evidence of association with type 2 diabetes from these six regions published by Zeggini et al. [5] were not included in the type 1 diabetes meta-analysis. However, substitutes in linkage disequilibrium with these type 2 diabetes SNPs $\left(r^{2}>0.8\right.$ in the HapMap (http://www.hapmap.org, accessed 22 April 2009) Centre d'Etude du Polymorphisme Humain [CEPH] panel of 32 individuals) were included (ESM Table 2).

Only the THADA SNP rs17031005, which is in linkage disequilibrium with the type 2 diabetes-associated SNP rs7578597 in the THADA gene region $\left(r^{2}=1\right)$, showed evidence of association with type 1 diabetes in the metaanalysis by Cooper et al. [35] ( $p=4.79 \times 10^{-5}$; ESM Table 2). Therefore, we followed up this result by genotyping rs17031005 in 7,256 cases and 8,760 controls, and the type 2 diabetes-associated SNP rs7578597 in 7,601 British type 1 diabetes cases and 8,395 controls. The genotypes of samples, which were used by both the WTCCC and the present study, were compared at rs 17031005 and revealed $99.9 \%$ concordance between the studies. We found no evidence of association with type 1 diabetes at rs17031005 
$(p=0.606)$ either in the 5,442 cases and 6,239 controls who were not included in the type 1 diabetes meta-analysis by Cooper et al. [35] or in the full dataset of 7,256 cases and 8,760 controls $(p=0.078$; Table 1$)$. Similarly, rs 7578597 was not associated with type 1 diabetes $(p=0.113)$. As we found no association with type 1 diabetes, the type 1 diabetes meta-analysis result in the THADA gene region is likely to be a false-positive result [35] (ESM Table 2). Finally, a meta-analysis combining the 5,442 cases and 6,239 controls genotyped in the present study with the WTCCC and the US studies used by Cooper et al. [35] provided no additional support for association with type 1 diabetes at rs17031005 $(p=0.003)$. Furthermore, we found no evidence of interactions between the THADA SNPs and HLA class II genotypes ( $p>0.05$; ESM Table 5), age-atdiagnosis $(p>0.05$; ESM Table 6$)$, sex or autoantibody status $(p>0.05)$.

\section{Discussion}

We have investigated confirmed type 2 diabetes-associated SNPs for association with type 1 diabetes and interaction with sex, age-at-diagnosis, HLA class II genotypes and autoantibody status in a dataset larger than any previously published study. Yet, we have failed to find evidence of association between type 1 diabetes and these confirmed loci, with the possible exception of the PPARG rs 1801282 SNP. As the controls represent the British population, we expect approximately $3.4 \%$ to have or to develop type 2 diabetes (http://www.diabetes.org.uk/Professionals/Infor mation_resources/Reports/Diabetes-prevalence-2008/, accessed 22 April 2009). However, this only led to a very small loss of power $(<1 \%)$. Indeed, at the PPARG SNP, we had $87 \%$ power to exclude an effect as small as an OR of 1.14 at an $\alpha$ level of 0.003 and a MAF of 0.12 , while a recently published negative study analysing SNP rs2197423 in PPARG was powered to exclude effects with an OR of greater than 1.34 [36]. Hence, the present study was statistically well powered to detect effects as small as those reported for type 2 diabetes but was not powered to exclude effects with an OR of below 1.11 (Table 1).

The transcription factor PPAR $\gamma$ has been reported to have effects in type 2 diabetes, in the immune system, and in inflammation, as evidenced by its production in several types of immune cell. In macrophages, PPAR $\gamma$ regulates lipid metabolism and controls the inflammatory response, while in T cells it inhibits IL-2 secretion and can induce apoptosis. Type 2 diabetes treatments that act by binding to PPAR $\gamma$, which belong to the thiazolidinedione class of drugs, have been investigated in the treatment of several autoimmune diseases. Human psoriasis cases showed reduced plaque formation when treated with pioglitazone
[37]. PPAR $\gamma$ may have multiple targets in rheumatoid arthritis (RA), as it regulates the key RA mediators TNF- $\alpha$, IL-1 $\beta$ and IL-6 [38]. Troglitazone reduced adjuvantinduced arthritis in the Lewis rat model [39], and rosiglitazone reduced colitis in a murine model of inflammatory bowel disease $[38,40]$. More specifically, the larger of the two PPAR $\gamma$ isoforms $(\gamma 2)$ is the only one to express the region of the gene containing the rs1801282/Pro12Ala SNP. This isoform is predominantly expressed in fat cells. An increase in the production of the Ala12 variant of the $\gamma 2$ isoform, which confers a $25 \%$ reduced risk of type 2 diabetes, is known to improve insulin sensitivity [41]. Improved insulin sensitivity could provide some protection against type 1 diabetes.

Wenzlau et al. [33] found that SLC30A8, which encodes the ZnT8 autoantigen, is highly expressed in the pancreas. They also reported that antibodies to ZnT8 are detectable at a very young age in type 1 diabetic patients, frequently before 3 years [33]. Wenzlau et al. [32] later identified rs 13266634 as the SNP responsible for the type 1 diabetes autoimmune response to ZnT8 [32]. In contrast to the findings of Wenzlau et al. [32, 33] and Gohlke et al. [34], our results suggest that altering the specificity of the ZnT8 autoantibody via SLC30A8 SNP rs13266634 does not alter the risk of type 1 diabetes, even in individuals diagnosed with type 1 diabetes at a very young age (0-4 years) (ESM Table 6), or by HLA class II genotype (ESM Table 5).

Whilst we have investigated SNPs in 12 of the type 2 diabetes-associated gene regions for association with type 1 diabetes, it is possible that these regions also contain type 1 diabetes causal variants that do not affect type 2 diabetes. However, this is not evident in the results from the meta-analysis of up to 3,565 type 1 diabetes cases and 4,657 controls [35]. Equally, as these SNPs explain less than $10 \%$ of genetic variation [42] in type 2 diabetes risk, there may be undiscovered type 2 diabetes loci associated with type 1 diabetes. Finally, as all our type 1 diabetic patients were paediatric cases, we cannot rule out the possibility that type 2 diabetes genes affect adult-onset type 1 diabetes. One recent report suggested that TCF7L2 may be associated with latent autoimmune diabetes in adults, a form of type 1 diabetes that is diagnosed in individuals aged $>35$ years [2]. This result, however, may have been due to a small number of type 2 diabetes cases included in the study [43]. Our results, and those of a recent study of type 1 diabetes loci in type 2 diabetes cases and controls [44], nevertheless indicate that type 2 diabetes susceptibility loci do not make a substantial contribution to the risk of paediatric type 1 diabetes.

Acknowledgements This work was funded by the Juvenile Diabetes Research Foundation (JDRF) International, the Wellcome Trust, and 
the National Institute for Health Research Cambridge Biomedical Research Centre. The Cambridge Institute for Medical Research (CIMR) is in receipt of a Wellcome Trust Strategic Award (079895). We are grateful for the participation of the type 1 diabetic patients and the control individuals, and especially thank the Human Biological Data Interchange for providing blood samples from the USA multiplex families and Diabetes UK for providing blood samples from the UK multiplex families, the Norwegian Study Group for Childhood Diabetes for providing DNA from Norwegian families (D. Undlien and K Rønningen), GET1FIN (J. Tuomilehto, L. Kinnunen, E. Tuomilehto-Wolf, V. Harjutsalo, and T. Valle) for the provision of Finnish samples, funded by the Academy of Finland, the Sigrid Juselius Foundation, and the JDRF; and D. Savage, C. Patterson, D. Carson and P. Maxwell for providing Northern Irish samples. We would like to thank the Medical Research Council and Wellcome Trust for funding the collection of DNA from the British 1958 Birth Cohort. We are also grateful to C. Eftychi (JDRF/WT Diabetes and Inflammation Laboratory) for her help in genotyping, and P. Bingley (Department of Clinical Science, University of Bristol) for measurement of GAD and IA-2 autoantibodies. DNA control samples were provided by: S. Ring, R. Jones, M. Pembrey, W. McArdle, D. Strachan and P. Burton from the Avon and Longitudinal Study of Parents and Children Laboratory in Bristol and the British 1958 Birth Cohort team. DNA samples were prepared by K. Bourget, S. Duley, M. Hardy, S. Hawkins, S. Hood, E. King, T. Mistry, A. Simpson, S. Wood, P. Lauder, S. Clayton, F. Wright and C. Collins.

This research uses resources provided by the Type 1 Diabetes Genetics Consortium, a collaborative clinical study sponsored by the National Institute of Diabetes and Digestive and Kidney Diseases (NIDDK), National Institute of Allergy and Infectious Disease (NIAID), National Human Genome Research Institute (NHGRI), National Institute of Child Health and Human Development (NICHD), and JDRF International and supported by U01 DK062418.

Duality of interest The authors declare that there is no duality of interest associated with this manuscript.

Open Access This article is distributed under the terms of the Creative Commons Attribution Noncommercial License which permits any noncommercial use, distribution, and reproduction in any medium, provided the original author(s) and source are credited.

\section{References}

1. Donath MY, Storling J, Maedler K, Mandrup-Poulsen T (2003) Inflammatory mediators and islet beta-cell failure: a link between type 1 and type 2 diabetes. J Mol Med 81:455-470

2. Cervin C, Lyssenko V, Bakhtadze E et al (2008) Genetic similarities between latent autoimmune diabetes in adults, type 1 diabetes, and type 2 diabetes. Diabetes 57:1433-1437

3. Chiu HK, Tsai EC, Juneja R et al (2007) Equivalent insulin resistance in latent autoimmune diabetes in adults (LADA) and type 2 diabetic patients. Diabetes Res Clin Pract 77:237-244

4. Zeggini E, Weedon MN, Lindgren CM et al (2007) Replication of genome-wide association signals in UK samples reveals risk loci for type 2 diabetes. Science 316:1336-1341

5. Zeggini E, Scott LJ, Saxena R et al (2008) Meta-analysis of genomewide association data and large-scale replication identifies additional susceptibility loci for type 2 diabetes. Nat Genet 40:638-645

6. Unoki H, Takahashi A, Kawaguchi $\mathrm{T}$ et al (2008) SNPs in $K C N Q 1$ are associated with susceptibility to type 2 diabetes in East Asian and European populations. Nat Genet 40:1098-1102
7. Yasuda K, Miyake K, Horikawa Y et al (2008) Variants in KCNQ1 are associated with susceptibility to type 2 diabetes mellitus. Nat Genet 40:1092-1097

8. Scott LJ, Mohlke KL, Bonnycastle LL et al (2007) A genomewide association study of type 2 diabetes in Finns detects multiple susceptibility variants. Science 316:1341-1345

9. Grant SF, Thorleifsson G, Reynisdottir I et al (2006) Variant of transcription factor 7-like 2 (TCF7L2) gene confers risk of type 2 diabetes. Nat Genet 38:320-323

10. Hertel JK, Johansson S, Raeder H et al (2008) Genetic analysis of recently identified type 2 diabetes loci in 1, 638 unselected patients with type 2 diabetes and 1, 858 control participants from a Norwegian population-based cohort (the HUNT study). Diabetologia 51:971-977

11. Steinthorsdottir V, Thorleifsson G, Reynisdottir I et al (2007) A variant in CDKAL1 influences insulin response and risk of type 2 diabetes. Nat Genet 39:770-775

12. Sandhu MS, Weedon MN, Fawcett KA et al (2007) Common variants in WFS1 confer risk of type 2 diabetes. Nat Genet 39:951-953

13. Gudmundsson J, Sulem P, Steinthorsdottir V et al (2007) Two variants on chromosome 17 confer prostate cancer risk, and the one in TCF2 protects against type 2 diabetes. Nat Genet 39:977983

14. Frayling TM (2007) Genome-wide association studies provide new insights into type 2 diabetes aetiology. Nat Rev Genet 8:657662

15. Saxena R, Voight BF, Lyssenko V et al (2007) Genome-wide association analysis identifies loci for type 2 diabetes and triglyceride levels. Science 316:1331-1336

16. Sladek R, Rocheleau G, Rung J et al (2007) A genome-wide association study identifies novel risk loci for type 2 diabetes. Nature 445:881-885

17. Eftychi C, Howson JMM, Barratt BJ et al (2004) Analysis of the type 2 diabetes-associated single nucleotide polymorphisms in the genes IRS1, KCNJ11, and PPARG2 in type 1 diabetes. Diabetes 53:870-873

18. Field SF, Howson JMM, Smyth DJ, Walker NM, Dunger DB, Todd JA (2007) Analysis of the type 2 diabetes gene, TCF7L2, in 13, 795 type 1 diabetes cases and control subjects. Diabetologia $50: 212-213$

19. Field SF, Howson JMM, Walker NM, Dunger DB, Todd JA (2007) Analysis of the obesity gene FTO in 14, 803 type 1 diabetes cases and controls. Diabetologia 50:2218-2220

20. Wellcome Trust Case Control Consortium (2007) Genome-wide association study of 14,000 cases of seven common diseases and 3,000 shared controls. Nature 447:661-678

21. Clayton DG, Walker NM, Smyth DJ et al (2005) Population structure, differential bias and genomic control in a large-scale, case-control association study. Nat Genet 37:1243-1246

22. Nejentsev S, Howson JMM, Walker NM et al (2007) Localization of type 1 diabetes susceptibility to the MHC class I genes $H L A-B$ and HLA-A. Nature 450:887-892

23. Monsuur AJ, de Bakker PI, Zhernakova A et al (2008) Effective detection of human leukocyte antigen risk alleles in celiac disease using tag single nucleotide polymorphisms. PLoS ONE 3:e2270

24. Bingley PJ, Bonifacio E, Williams AJ, Genovese S, Bottazzo GF, Gale EA (1997) Prediction of IDDM in the general population: strategies based on combinations of autoantibody markers. Diabetes 46:1701-1710

25. Bingley PJ, Williams AJ, Gale EA (1999) Optimized autoantibody-based risk assessment in family members. Implications for future intervention trials. Diabetes Care 22:1796-1801

26. Taplin CE, Barker JM (2008) Autoantibodies in type 1 diabetes. Autoimmunity 41:11-18 
27. Howson JMM, Dunger DB, Nutland S, Stevens H, Wicker LS, Todd JA (2007) A type 1 diabetes subgroup with a female bias is characterised by failure in tolerance to thyroid peroxidase at an early age and a strong association with the cytotoxic Tlymphocyte-associated antigen-4 gene. Diabetologia 50:741-746

28. Cordell HJ, Clayton DG (2002) A unified stepwise regression procedure for evaluating the relative effects of polymorphisms within a gene using case/control or family data: application to HLA in type 1 diabetes. Am J Hum Genet 70:124-141

29. Woolf B (1955) On estimating the relation between blood group and disease. Ann Hum Genet 19:251-253

30. Smyth DJ, Cooper JD, Howson JM et al (2008) PTPN22 Trp ${ }^{620}$ explains the association of chromosome $1 \mathrm{p} 13$ with type 1 diabetes and shows a statistical interaction with HLA class II genotypes. Diabetes 57:1730-1737

31. Koeleman BP, Lie BA, Undlien DE et al (2004) Genotype effects and epistasis in type 1 diabetes and HLA-DQ trans dimer associations with disease. Genes Immun 5:381-388

32. Wenzlau JM, Liu Y, Yu L et al (2008) A common nonsynonymous single nucleotide polymorphism in the SLC30A8 gene determines ZnT8 autoantibody specificity in type 1 diabetes. Diabetes 57:2693-2697

33. Wenzlau JM, Juhl K, Yu L et al (2007) The cation efflux transporter ZnT8 (Slc30A8) is a major autoantigen in human type 1 diabetes. Proc Natl Acad Sci U S A 104:17040-17045

34. Gohlke H, Ferrari U, Koczwara K, Bonifacio E, Illig T, Ziegler AG (2008) SLC30A8 (ZnT8) polymorphism is associated with young age at type 1 diabetes onset. Rev Diabet Stud 5:25-27
35. Cooper JD, Smyth DJ, Smiles AM et al (2008) Meta-analysis of genome-wide association study data identifies additional type 1 diabetes risk loci. Nat Genet 40:1399-1401

36. Qu HQ, Grant SF, Bradfield JP et al (2008) Association analysis of type 2 diabetes loci in type 1 diabetes. Diabetes 57:19831986

37. Robertshaw H, Friedmann PS (2005) Pioglitazone: a promising therapy for psoriasis. Br J Dermatol 152:189-191

38. Szeles L, Torocsik D, Nagy L (2007) PPAR $\gamma$ in immunity and inflammation: cell types and diseases. Biochim Biophys Acta 1771:1014-1030

39. Kawahito Y, Kondo M, Tsubouchi Y et al (2000) 15-deoxy- $\Delta 12$, 14-PGJ2 induces synoviocyte apoptosis and suppresses adjuvantinduced arthritis in rats. J Clin Invest 106:189-197

40. Su CG, Wen X, Bailey ST et al (1999) A novel therapy for colitis utilizing PPAR- $\gamma$ ligands to inhibit the epithelial inflammatory response. J Clin Invest 104:383-389

41. Stumvoll M, Häring $H$ (2002) The peroxisome proliferatoractivated receptor- $\gamma 2$ Pro12Ala polymorphism. Diabetes 51:2341-2347

42. Prokopenko I, McCarthy MI, Lindgren CM (2008) Type 2 diabetes: new genes, new understanding. Trends Genet 24:613-621

43. Steck AK, Eisenbarth GS (2008) Genetic similarities between latent autoimmune diabetes and type 1 and type 2 diabetes. Diabetes 57:1160-1162

44. Rafiq S, Melzer D, Weedon MN et al (2008) Gene variants influencing measures of inflammation or predisposing to autoimmune and inflammatory diseases are not associated with the risk of type 2 diabetes. Diabetologia 51:2205-2213 